\title{
IN SITU RAMAN MICROSCOPY OF A SINGLE GRAPHITE MICROFLAKE ELECTRODE IN A $\mathrm{Li}^{+}$-CONTAINING ELECTROLYTE
}

\author{
Qingfang Shi, Kaoru Dokko, and Daniel A. Scherson \\ Department of Chemistry \\ Case Western Reserve University \\ Cleveland, $\mathrm{OH}$ 44106-7078
}

\begin{abstract}
Highly detailed Raman spectra from a single KS-44 graphite microflake electrode as a function of the applied potential have been collected in situ using a Raman microscope and a sealed spectroelectrochemical cell isolated from the laboratory environment. Correlations were found between the Raman spectral features and the various $\mathrm{Li}^{+}$intercalation stages while recording in real time Raman spectra during a linear potential scan from 0.7 down ca. $0.0 \mathrm{~V}$ vs ${\mathrm{Li} / \mathrm{Li}^{+}}^{+}$at a rate of $0.1 \mathrm{mV} / \mathrm{s}$ in a $1 \mathrm{M} \mathrm{LiClO}_{4}$ solution in a $1: 1$ (by volume) ethylene carbonate (EC):diethyl carbonate (DEC) mixture. In particular, clearly defined isosbestic points were observed for data collected in the potential range where the transition between dilute phase 1 and phase 4 of lithiated graphite is known to occur, i.e. $0.157<\mathrm{E}<0.215 \mathrm{vs} \mathrm{Li}^{2} \mathrm{Li}^{+}$. Statistical analysis of the spectroscopic data within this region made it possible to determine independently the fraction of each of the two phases present as a function of potential without relying on coulometric information and then predict, based on the proposed stoichiometry for the transition, a spectrally-derived voltammetric feature.
\end{abstract}

\section{INTRODUCTION}

Continuing progress is being made in our laboratories toward developing Raman microscopy as a time-, and space-resolved probe of electrodes within actual battery environments. ${ }^{1,2}$ Much of the impetus for research in this area stems from the possibility of visualizing charge flow within energy storage devices during operation, which may serve to

This report is a preprint of an article submitted to a journal for publication. Because of changes that may be made before formal publication, this preprint is made available with the understanding that it will not be cited or reproduced without the permission of the author. 
validate and/or refine theoretical models aimed at predicting from first principles their electrical response. Raman scattering affords a convenient means of monitoring the incorporation and release of $\mathrm{Li}^{+}$from a variety of host lattices, including transition metal oxides ${ }^{3-10}$ and graphite, ${ }^{11-14}$ as, in most instances, changes in the molar fraction of $\mathrm{Li}^{+}$elicit corresponding modifications in the spectral properties of the materials. Useful information has been gained from spectroelectrochemical experiments under steady state conditions, allowing direct correlations to be made between spectra and state of charge of (or equivalently extent of $\mathrm{Li}^{+}$intercalation within) specimens containing the same constituents as those found in practical electrodes. ${ }^{1,12-14}$ More recently, interfering effects due to binders and additives have been eliminated by embedding ensembles of individual particles into judiciously selected substrates. ${ }^{11,12,15}$ In fact, the use of a Raman microscope attachment has made it possible to focus the exciting laser radiation onto individual particles in such ensembles enabling certain aspects of the dynamics of $\mathrm{Li}^{+}$ intercalation within such single particles to be monitored in real time. ${ }^{12}$ One of the disadvantages of this latter strategy is that the electrochemical response represents a convolution of all particles within the ensemble making it difficult to correlate the recorded spectra with the observed current. An approach that can overcome part of these difficulties, developed by Uchida and coworkers, combines micromanipulation techniques with microelectrodes to perform electrochemical experiments on single microparticle electrodes. ${ }^{16-19}$ In fact, implementation of some of those methodologies in our laboratory culminated recently in the first in situ Raman spectroelectrochemical experiments of single particle $\mathrm{Li}^{+}$intercalation electrodes using a lithiated Mn oxide as a model system. ${ }^{20}$ The extraordinary high quality of the spectra acquired in that study provided clear evidence that in the range $15<$ SOD $<45 \%$, where SOD represents the state of discharge (in percent) of the nominally fully charged material, i.e. $\lambda-\mathrm{MnO}_{2}$, two distinct phases of lithiated metal oxide coexist, in agreement with information derived from in situ X-ray diffraction 
(XRD) measurements involving more conventional battery-type electrodes. This contribution extends the procedures therein described to a single $\mathrm{KS}-44$ graphite microflake using a spectroelectro-chemical cell specifically designed to isolate the cell components and electrolyte from the laboratory environment. As will be shown, highly detailed voltammetric and Raman scattering information recorded simultaneously were found to be in excellent agreement with data reported in the literature for both techniques applied independently.

\section{EXPERIMENTAL}

The spectroelectrochemical cell used in these measurements was the same as that described earlier for experiments involving lithiated Mn oxide in non-aqueous electrolytes. ${ }^{20}$ In order to avoid problems with $\mathrm{Li}$ alloy formation, a $\mathrm{Ni}$ (instead of an $\mathrm{Au}$ ) microelectrode was used as the current collector. This $\mathrm{Ni}$ microelectrode was fabricated by inserting a thin $\mathrm{Ni}$ wire $(50 \mu \mathrm{m}$ in diameter) into a glass tube and the heating the tip of the tube in a hydrogen flame above the melting point to totally encapsulate the $\mathrm{Ni}$ wire. Once allowed to cool down to room temperature the tip was polished with sandpaper (CARBIMET, Grit600) to expose a flat, circularly shaped surface. Once installed in the cell, the Ni microelectrode was turned upward (surface facing up) under a regular microscope and a single KS-44 microflake placed in its center. Immediately thereafter, the sapphire window (Esco Products Inc., $0.5 \mathrm{~mm}$ thick) was positioned above the flake/electrode and pressed downward against the cell body via an O-ring (KALREZ ${ }^{\circledR}$ ) using a clamp to trap firmly the flake between the window and the Ni current collector. This assembly was then transferred to a high quality Ar-filled glove box, where the cell was filled with a $1 \mathrm{M}$ $\mathrm{LiClO}_{4}$ solution in a 1:1 (by volume) ethylene carbonate (EC): diethyl carbonate (DEC) mixture. A piece of Li metal foil $\left(2 \mathrm{~cm}^{2}\right)$ pressed against a tungsten wire current collector was used as the counter/reference electrode. Once carefully sealed, the cell was removed from the glove box for the spectroelectrochemical experiments. 
The first linear potential scan of the graphite microflake was performed starting at $2.5 \mathrm{~V}$ in the negative direction down to ca. $0.0 \mathrm{~V}$ at a rate $v=0.5 \mathrm{mV} / \mathrm{s}$, at which point the scan was reversed up to $0.7 \mathrm{~V}$ at the same scan rate. Two voltammetric cycles were then recorded in the range $0.7>\mathrm{E}>0.0 \mathrm{~V}$ at $v=0.2 \mathrm{mV} / \mathrm{s}$. Once the potential returned to $0.7 \mathrm{~V}, v$ was further reduced to $0.1 \mathrm{mV} / \mathrm{s}$ and a single linear scan performed down to $0.0 \mathrm{~V}$ while acquiring in situ Raman spectra continuously.

As described in detail elsewhere, ${ }^{21}$ Raman spectra were recorded using a Raman 2000 system (Chromex Inc., Albuquerque, NM) incorporating a microscope attachment, using the 532 $\mathrm{nm}$ beam of a Verdi laser (Coherent) focused through 20X Olympus microscope onto a KS-44 microflake (spot size of the beam was ca. $5 \mu \mathrm{m}$ diameter) as the excitation source at powers on the sample of about $3 \mathrm{~mW}$. The integration time for each frame was $15 \mathrm{~s}$ with four frames coadded to improve the signal to noise ratio. The electrode potential was controlled with a conventional potentiostat (AFRDE5, Pine Instruments), and all measurements were carried out at room temperature.

Statistical analysis of the spectra collected between $0.215 \mathrm{~V}$ and $0.174 \mathrm{~V}$ was performed with the classical least squares under Matlab.

\section{RESULTS AND DISCUSSION}

Shown in panels A through E in Fig. 1 are a series of in situ Raman spectra recorded continuously for a KS-44 graphite microflake in $1 \mathrm{M} \mathrm{LiClO}_{4}$ solution in a DEC/EC mixture (1:1 by volume) during the fourth linear voltammetric scan in the negative direction at a scan rate of $0.1 \mathrm{mV} / \mathrm{s}$ (see Fig. 2). For clarity, the potentials at which the spectra in Fig. 1 were collected have been specified for only a limited number of curves. Other values can, nevertheless, be calculated by assuming a $6 \mathrm{mV}$ difference between adjacent spectra. Although subject to some error, owing to uncertainties in the actual shape of the background current (expected to have contributions due 
to processes other than simple $\mathrm{Li}^{+}$intercalation, such as, electrochemically-induced electrolyte decomposition) coulometric analysis of the voltammetric peak centered at about $0.21 \mathrm{~V}$ vs $\mathrm{Li}^{2} / \mathrm{Li}^{+}$, attributed to the Stage $1 \rightarrow$ Stage 4 phase transition, ${ }^{22}$

$$
\mathrm{LiC}_{72}+\mathrm{Li}^{+}+\mathrm{e}^{-} \rightarrow 2 \mathrm{LiC}_{36}
$$

yielded a charge $Q=0.55 \mu \mathrm{C}$. On this basis, and given that the density of graphite is $2.25 \mathrm{~g} / \mathrm{cm}^{3}$, the weight of the microflake can be estimated to be of ca. $4.9 \mathrm{ng}$; hence, since the diameter of the fairly circular microflake is ca. $50 \mu \mathrm{m}$, i.e. cross sectional area of $2 \times 10^{-5} \mathrm{~cm}^{2}$, its thickness would be of ca. $1 \mu \mathrm{m}$. Although reasonable, no attempts were made to measure this value by other means.

Close inspection of both the Raman and electrochemical data in these figures revealed excellent agreement with results reported by other groups using larger, more conventional electrodes, ${ }^{13,14}$ providing strong evidence that the methods and procedures employed in this work are indeed highly reliable. In particular,

i. The Raman spectra of the KS-44 microflake down to ca. $0.22 \mathrm{~V}$ (see Panels A - C), exhibit a single prominent peak at $1580 \mathrm{~cm}^{-1}$ ascribed (primarily) to the $E_{2 \mathrm{~g} 2}$ mode of graphite. The asymmetric character of this peak is caused by the presence of a second feature centered at about $1604 \mathrm{~cm}^{-1}(\mathrm{X})$ attributed to electrochemically-induced irreversible changes in the graphite induced by $\mathrm{Li}^{+}$-intercalation into the lattice during the first scan in the negative direction. The relative contributions of the $\mathrm{E}_{2 \mathrm{~g} 2}$ and $\mathrm{X}$ features to the observed signal for spectra collected at four different potentials are shown in Fig. A, Supplementary Material (see also Item ii. below).

ii. The peak position (PP) and full width at half height (FWHH) of the $E_{2 g 2}$ peak remained virtually constant in the potential range $0.7>\mathrm{E}>0.58 \mathrm{~V}$ vs $\mathrm{Li} / \mathrm{Li}^{+}$, i.e. no evidence for $\mathrm{Li}^{+}$intercalation into the graphite lattice; however, its integrated intensity, 
$\mathrm{I}\left(\mathrm{E}_{2 \mathrm{~g} 2}\right)$ was found to increase by ca. $10 \%$ down to $0.5 \mathrm{~V}$ vs $\mathrm{Li}^{2} \mathrm{Li}^{+}$(see open circles in Fig B, Supplementary Material). Also shown in that figure are the corresponding plots of $\mathrm{I}(\mathrm{X})$ as well as the total integrated intensity of the asymmetric feature $\mathrm{I}\left(\mathrm{E}_{2 \mathrm{~g} 2}\right)$ and $I(X)$ as a function of potential to illustrate the fact that the overall increase in integrated intensity is derived from $\mathrm{I}\left(\mathrm{E}_{2 \mathrm{~g}}\right)$.

iii. As shown in Fig. 3 (solid circles, right ordinate), $\mathrm{FWHH}\left(\mathrm{E}_{2 \mathrm{~g} 2}\right)$ decreased linearly in the range $0.4<\mathrm{E}<0.6 \mathrm{~V}$, remained relatively constant down to $0.35 \mathrm{~V}$ and then increased down to $0.25 \mathrm{~V}$. In contrast, $\mathrm{PP}\left(\mathrm{E}_{2 \mathrm{~g}^{2}}\right)$ increased linearly over the range $0.5-$ $0.25 \mathrm{~V}$ vs $\mathrm{Li} / \mathrm{Li}^{+}$at a rate of ca. $-30 \mathrm{~cm}^{-1} / \mathrm{V}$ (see solid line for which; Intercept: 1596.5 $\mathrm{cm}^{-1}$, Correlation Coefficient: 0.9984 ), a behavior characteristic of dilute stage 1 (also known as Phase VIII), ${ }^{22}$ of the Li-graphite phase diagram. ${ }^{23}$

iv. At potentials between 0.25 and $0.20 \mathrm{~V}$, the $\mathrm{E}_{2 \mathrm{~g} 2}$ feature (see Panel D, Fig. 1) was found to gradually disappear, leading to the simultaneous emergence of two peaks centered at around 1601 and $1577 \mathrm{~cm}^{-1}$ (see below) attributed, respectively, to bounding and interior modes of stage 4 of the Li-graphite system. ${ }^{13}$

v. Within the range 0.170 down to 0.109 , the interior mode of phase 4 decreased in intensity rendering a spectrum displaying a single feature ascribed to phase 2 .

vi. Further excursion into even more negative potentials led to the total disappearance of features in the spectral region about $1600 \mathrm{~cm}^{-1}$; however, as clearly noted, a new peak (identified here for the first time) emerged at $1850 \mathrm{~cm}^{-1}$ (see Panel E, Fig. 1). Although this new feature cannot at this stage be assigned, data not shown in this work revealed that this latter peak disappears upon scanning the potential positive, pointing to the reversible character of the process(es) responsible for its occurrence. 
Although the development of procedures for the acquisition of in situ Raman spectra of a single graphite microflake, such as those implemented in this work, may be regarded in themselves as significant, the direct correspondence between the spectral features observed and the extent of $\mathrm{Li}^{+}$intercalation can offer new insights into thermodynamic and dynamic aspects of the $\mathrm{Li}$ /graphite system. In particular, strong evidence for a quantitative interconversion between stage 1 and stage 4 was obtained from the presence of two clearly-defined isosbestic points at 1597 and $1580 \mathrm{~cm}^{-1}$ for spectra collected in the range $0.215 \leq \mathrm{E} \leq 0.157 \mathrm{~V}$, as shown in overlapping form in Fig. 4. It becomes then possible to extract by statistical means (see Experimental Section) the amounts of each of the phases as a function of the applied potential, assuming the curves at $\mathrm{E}=0.215$ and $0.157 \mathrm{~V}$ represent the spectra of pure stage 1 and pure stage 4, respectively. Three illustrative examples of such spectral decomposition are shown in Fig. 5, where the scattered points are the experimental data, and the thick solid line through them is the statistical fit in terms of contributions arising from stage 1 (dotted line) and stage 4 (thin solid line).

Plots of the fractions of dilute stage 1 (left ordinate) and stage 4 (right ordinate) determined independently based on the statistical analysis of spectral data shown in Fig. 4 (and 5) are given in Fig. 6. A similar tactic was employed recently for the quantitative analysis of the Phase $1 \leftrightarrow$ Phase 2 transition for $\mathrm{LiMn}_{2} \mathrm{O}_{4}$ based on in situ Raman data recorded for a single microparticle of the material. ${ }^{20}$

As has been pointed out in the literature, the stage $1 \rightarrow$ stage 4 transition corresponds to peak A in the linear scan given in Fig. 2. ${ }^{22}$ A direct correlation between spectral and electrochemical data can be drawn by first fitting the experimental points to an arbitrary non-linear function and then taking the derivative of the data in Fig. 6. As shown in Fig. 7, the results yielded two virtually overlapping peaks (only one is shown here) derived either from stage 1 or independently 
from stage 4. Renormalization of the resulting feature to match the current maximum in peak A in the voltammogram, yielded a value of FWHH almost identical to that found for the voltammetric peak. However, as clearly evident in Fig. 7, the peak position extracted from the spectral data is about $10 \mathrm{mV}$ more negative than that in the actual voltammogram. This slight shift is in all likelihood caused by a diffusional delay, i.e. the scan rate is still too fast compared to the time constant for mass transport of $\mathrm{Li}^{+}$within the graphite lattice. In other words equilibrium is only attained at a time longer, and thus at a more negative potential than that prescribed under strict steady state conditions. This diffusional lag could in principle be reduced by slowing down the scan rate; unfortunately, the much longer times required for a complete acquisition would make this approach highly impractical.

\section{SUMMARY}

Quantitative analysis of in situ Raman spectra of a single KS-44 microflake electrode in a $1 \mathrm{M} \mathrm{LiClO}_{4}$ solution in a 1:1 (by volume) ethylene carbonate (EC):diethyl carbonate (DEC) mixture, made it possible to correlate features recorded over the potential region in which the stage 1 to stage 4 transition of the $\mathrm{Li} /$ graphite system is known to occur, i.e. $0.157<\mathrm{E}<0.215$ vs $\mathrm{Li} / \mathrm{Li}^{+}$, with a prominent peak in the voltammogram of this material centered at ca. $0.21 \mathrm{~V}$. This study provides yet another illustration of the power of Raman spectroscopy as a real time probe of intercalation phenomena in electrochemical environments. Efforts are currently under way to couple a computer controlled $\mathrm{X}-\mathrm{Y}$ translator to map in real time and with spatial resolution $\mathrm{Li}^{+}$ insertion into the graphite lattice using a microflake electrode in the same configuration as that described in this work. 


\section{REFERENCES}

(1) Luo, Y.; Cai, W.-B.; Xing, X.-K.; Scherson, D. A. Electrochem. Solid-State Lett. 2003 (in press)

(2) Cai, W.-B.; Shi, Q.; Mansuetto, M. F.; Scherson, D. A. Electrochem. Solid-State Lett. $2000,3,319$.

(3) Itoh, T.; Sato, H.; Nishina, T.; Matue, T.; Uchida, I. J Power Sources 1997, 68, 333.

(4) Kanoh, H.; Tang, W. P.; Ooi, K. Electrochem. Solid-State Lett. 1998, 1, 17.

(5) Totir, D. A.; Cahan, B. D.; Scherson, D. A. Electrochimica Acta 1999, 45, 161.

(6) Luo, Y.; Cai, W.-B.; Scherson, D. A. Electrochem. Solid-State Lett. 2001, 4, A101.

(7) Inaba, M.; Iriyama, Y.; Ogumi, Z.; Todzuka, Y.; Tasaka, A. J. Raman Spectr. 1997, 28, 613.

(8) Huang, W. W.; Frech, R. J. Power Sources 1999, 82, 616.

(9) Anzue, N.; Itoh, T.; Mohamedi, M.; Umeda, M.; Uchida, I. Solid State Ionics 2003, 156, 301.

(10) Dokko, K.; Mohamedi, M.; Anzue, N.; Itoh, T.; Uchida, I. J. Mat. Chem. 2002, 12, 3688.

(11) Totir, D. A.; Scherson, D. A. Electrochem. Solid-State Lett. 2000, 3, 263.

(12) Luo, Y.; Cai, W. B.; Scherson, D. A. J. Electrochem. Soc. 2002, 149, A1100.

(13) Inaba, M.; Yoshida, H.; Ogumi, Z.; Abe, T.; Mizutani, Y.; Asano, M. J. Electrochem. Soc. $1995,142,20$.

(14) Huang, W.; Frech, R. J. Electrochem. Soc. 1998, 145, 3312.

(15) Totir, D. A.; Cahan, B. D.; Scherson, D. A. Electrochim Acta 1999, 45, 161.

(16) Dokko, K.; Horikoshi, S.; Itoh, T.; Nishizawa, M.; Mohamedi, M.; Uchida, I. J. Power Sources 2000, 90, 109.

(17) Dokko, K.; Mohamedi, M.; Umeda, M.; Uchida, I. J. Electrochem. Soc 2003, 150, A425. 
(18) Dokko, K.; Nishizawa, M.; Mohamedi, M.; Umeda, M.; Uchida, I.; Akimoto, J.;

Takahashi, Y.; Gotoh, Y.; Mizuta, S. Electrochem. Solid-State Lett. 2001, 4, A151.

(19) Uchida, I.; Mohamedi, M.; Dokko, K.; Nishizawa, M.; Itoh, T.; Umeda, M. J. Power

Sources 2001, 97-8, 518.

(20) Dokko, K.; Shi, Q.; Stefan, I. C.; Scherson, D. A. J. Phys. Chem. 2003 (submitted)

(21) Luo, Y.; Cai, W.-B.; Scherson, D. A. Electrochem. Solid-State Lett. 2001, 4, A101.

(22) Levi, M. D.; Aurbach, D. J. Electroanal. Chem. 1997, 421, 79.

(23) Dahn, J. R. Phys. Rev. B. 1991, 44, 9170.

\section{ACKNOWLEDGEMENTS}

This work was supported in part by NASA-Glenn and the US Department of Energy,

Office of Basic Energy Sciences. Additional funding was provided by Eveready Battery

Company, Westlake, OH. K.D may wish to express his deep appreciation to Prof. Isamu Uchida

(Tohoku University) for his helpful comments. K.D. acknowledges a research fellowship from the Japan Society for the Promotion of Science.

\section{FIGURE CAPTIONS}

Fig. 1. Series of in situ Raman spectra for a KS-44 graphite microflake recorded in $1 \mathrm{M} \mathrm{LiClO}_{4}$ solution in a DEC/EC mixture (1:1 by volume), while acquiring the fourth linear voltammetric scan in the negative direction at a scan rate of $0.1 \mathrm{mV} / \mathrm{s}$ shown in Fig. 2 . The difference in average potential between two adjacent spectra is $6 \mathrm{mV}$. The arrows on the right hand side of each panel indicate the direction of the scan.

Fig. 2. Fourth linear voltammetric scan recorded in the negative direction at a scan rate of 0.1 $\mathrm{mV} / \mathrm{s}$ while acquiring the in situ Raman data in Fig. 1. 
Fig. 3. Plots of the peak position (open circles, left ordinate) and full width at half height (FWHH, full circles, right ordinate) of the $\mathrm{E}_{2 \mathrm{~g} 2}$ mode extracted from a statistical analysis of spectra collected over the region $0.25-0.7 \mathrm{~V}$. Within the region $0.5-0.25 \mathrm{~V}$ vs $\mathrm{Li} / \mathrm{Li}^{+}$, the $\mathrm{E}_{2 \mathrm{~g} 2}$ mode shifted linearly with potential (see solid line, slope $=-28.9 \mathrm{~cm}^{-1} / \mathrm{N}$; correlation coefficient $=0.9924$.

Fig. 4. In situ Raman spectra in the potential region in which dilute stage 1 and stage 4 coexist, i.e. $0.215-0.174 \mathrm{~V}$ vs $\mathrm{Li} / \mathrm{Li}^{+}$displayed in overlapping form to illustrate the presence of two clear isosbestic points at ca. 1580 and $1598 \mathrm{~cm}^{-1}$.

Fig. 5. Three illustrative examples of the decomposition of spectral data in the potential region in which stages 1 and 4 coexist. The scattered points are the experimental spectral data and the thick solid line through them is the statistical fit in terms of contributions arising from Stages 1 (dotted line) and 4 (thin solid line). The spectra of the pure phases were obtained from data recorded at the two extremes of the potential range (see text for details). The numbers next of each of the curves represent the contribution of each phase to the experimental data as determined by statistical means (see text for details)

Fig. 6. Plots of amount of the fraction of dilute stage 1 (left ordinate) and stage 4 (right ordinate) determined independently based on the statistical analysis of spectral data as shown in Fig. 4. Stage 1 and stage 4 phases are given by the spectra recorded at $E=0.215$ and 0.157 , respectively. The solid lines are best fits the data using arbitrary non-linear functions.

Fig. 7. Expanded plot of the voltammetric data in Fig. 2 in the range ca. $0.1725<\mathrm{E}<0.25 \mathrm{~V}$ (scattered points) and normalized voltammetric peak (solid line) as deduced from the statistical analyses of the spectroscopic data in Fig. 4 (see text for details).

\section{SUPPLEMENTARY MATERIAL}

\section{FIGURE CAPTIONS}


Fig. A. Deconvolution of four representative Raman spectra for the KS-44 microflake (see scattered points) in the potential region down to ca. $0.22 \mathrm{~V}$ in terms of the prominent 1580 $\mathrm{cm}^{-1}$ peak ascribed to the $\mathrm{E}_{2 \mathrm{~g} 2}$ mode of graphite (dotted line) and an additional feature centered at about $1604 \mathrm{~cm}^{-1}(\mathrm{X})$ attributed to electrochemically induced irreversible changes in the graphite induced by $\mathrm{Li}^{+}$-intercalation into the lattice during previous cycles (solid line) see text for additional details). The solid line through the scattered points represents the sum of the two best-fit components.

Fig. B. Plot of the integrated peak intensity (I) of the $E_{2 g 2}$ (open circles, left ordinate) and $X$ modes (solid circles, right ordinate) as a function of potential, extracted from a statistical analysis of spectra collected over the region $0.25-0.7 \mathrm{~V}$. Also shown in this figure is the total integrated intensity of the entire feature, i.e. $I\left(E_{2 g}\right)+I(X)$ (see solid squares, left ordinate). 

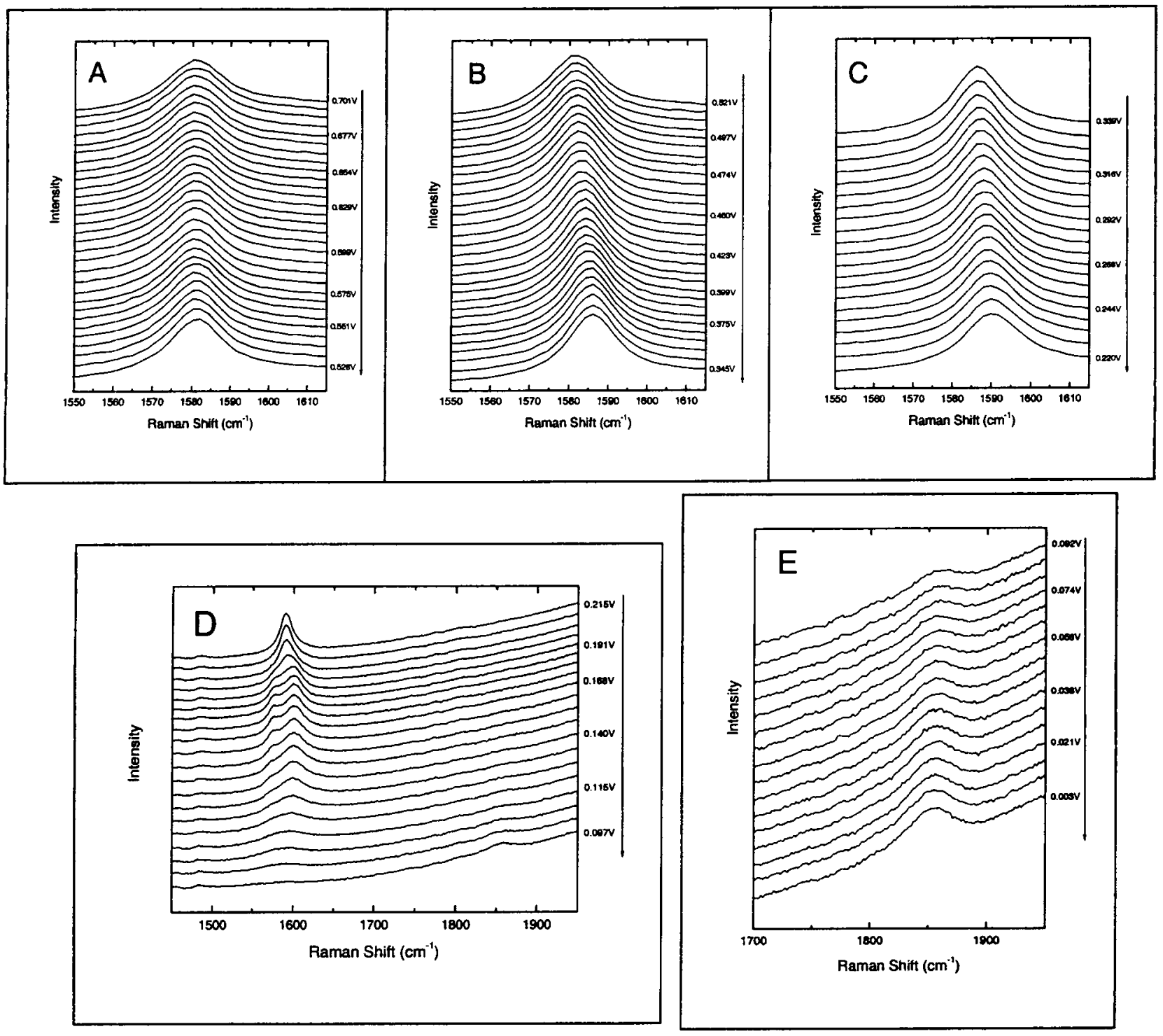

Fig. 1. Series of in situ Raman spectra for a KS-44 graphite microflake recorded in $1 \mathrm{M} \mathrm{LiClO}_{4}$ solution in a DEC/EC mixture (1:1 by volume), while acquiring the fourth linear voltammetric scan in the negative direction at a scan rate of $0.1 \mathrm{mV} / \mathrm{s}$ shown in Fig. 2 . The difference in average potential between two adjacent spectra is $6 \mathrm{mV}$. The arrows on the right hand side of each panel indicate the direction of the scan. 


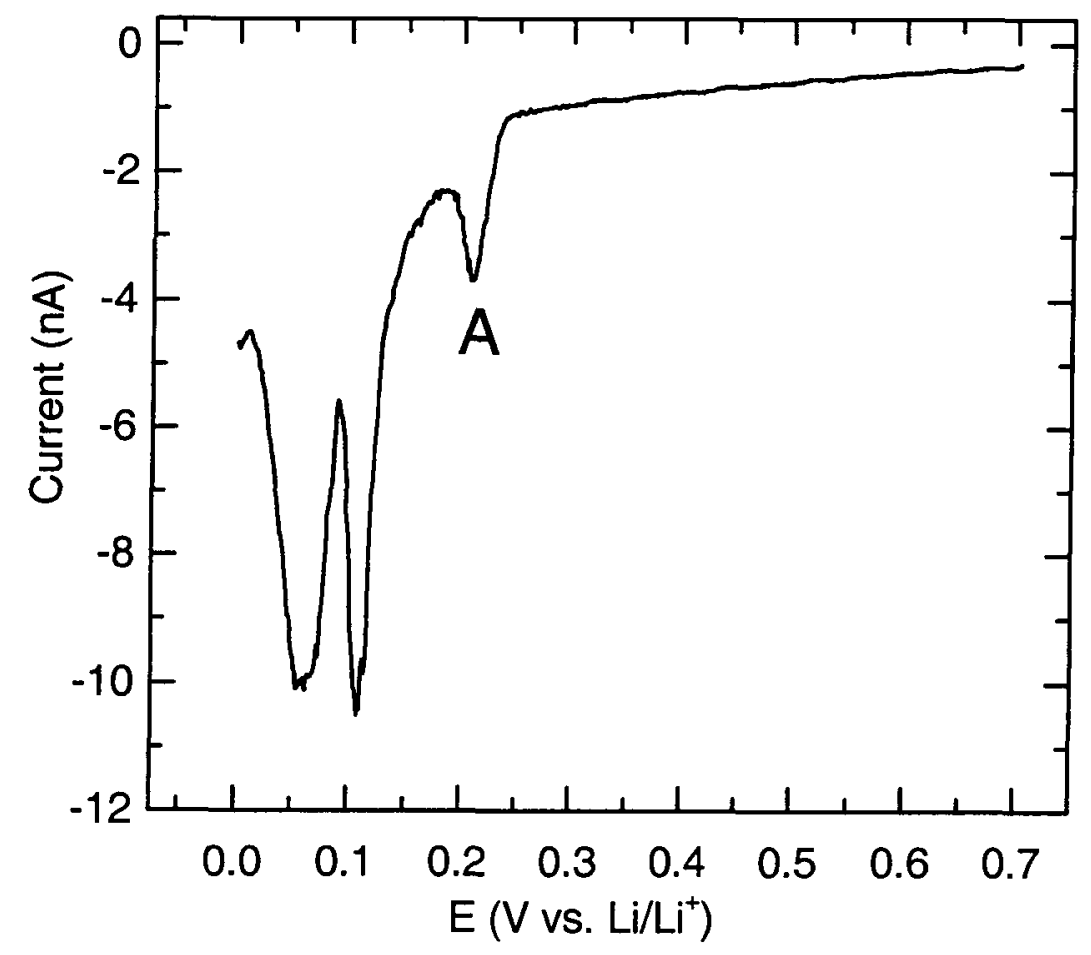

Fig. 2. Fourth linear voltammetric scan recorded in the negative direction at a scan rate of 0.1 $\mathrm{mV} / \mathrm{s}$, while acquiring the in situ Raman data in Fig. 1. 


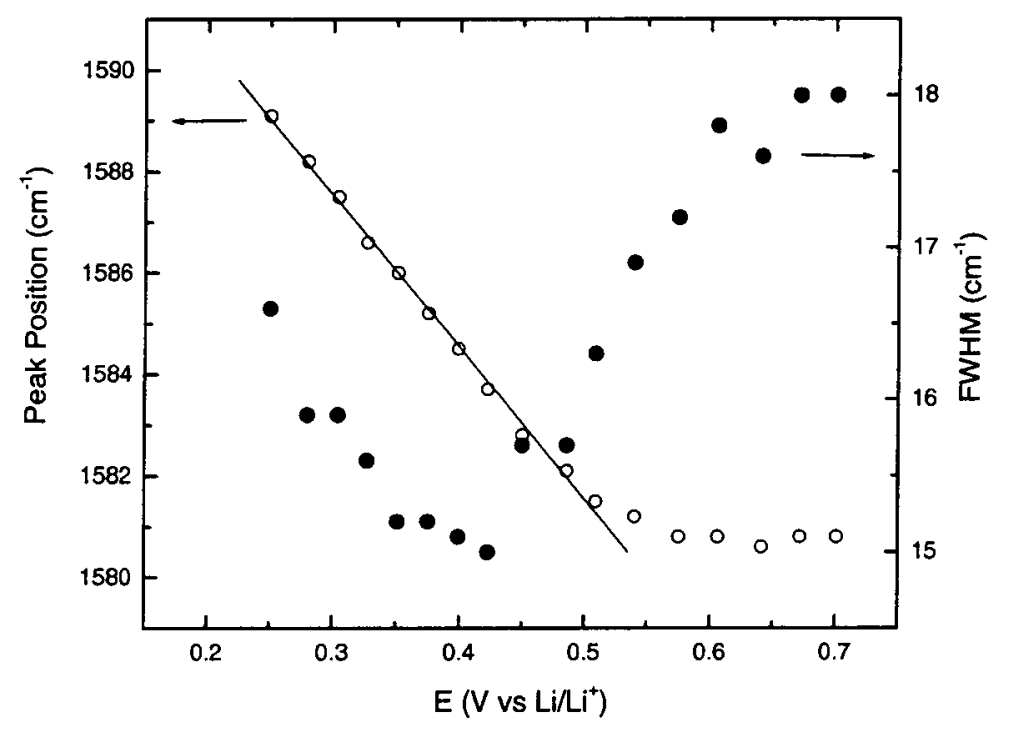

Fig. 3. Plots of the peak position (open circles, left ordinate) and full width at half height (FWHH, full circles, right ordinate) of the $\mathrm{E}_{2 \mathrm{~g} 2}$ mode extracted from a statistical analysis of spectra collected over the region $0.25-0.7 \mathrm{~V}$. Within the region $0.5-0.25 \mathrm{~V}$ vs $\mathrm{Li} / \mathrm{Li}^{+}$, the $\mathrm{E}_{2 \mathrm{~g} 2}$ mode shifted linearly with potential (the solid line represents the best fit to the data in the range $0.25 .<\mathrm{E}<0.5 ;$ slope $=$ $28.9 \mathrm{~cm}^{-1} / \mathrm{V}$; correlation coefficient $=0.9924$ ). 


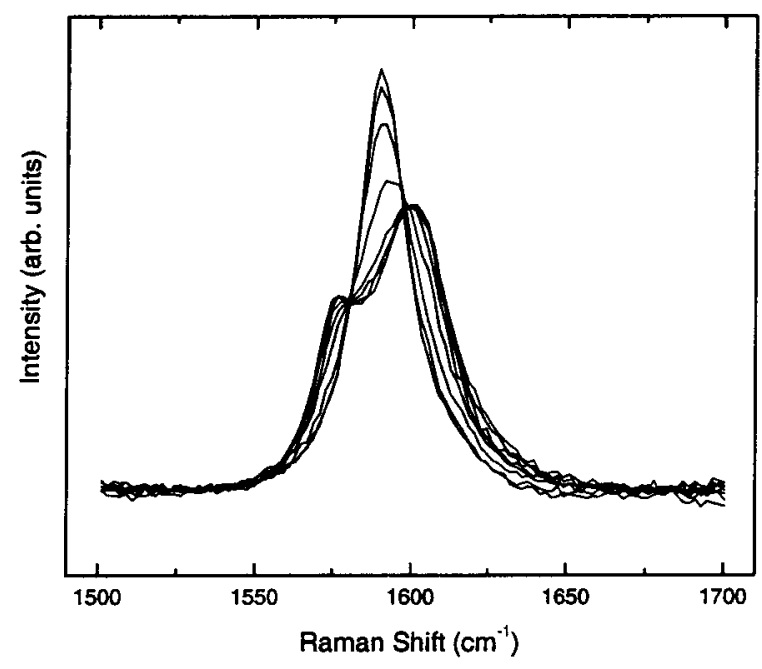

Fig. 4. In situ Raman spectra in the potential region in which dilute stage 1 and stage 4 coexist, i.e. $0.215-0.174 \mathrm{~V}$ vs $\mathrm{Li} / \mathrm{Li}^{+}$displayed in overlapping form to illustrate the presence of two clear isosbestic points at ca. 1580 and $1598 \mathrm{~cm}^{-1}$. 

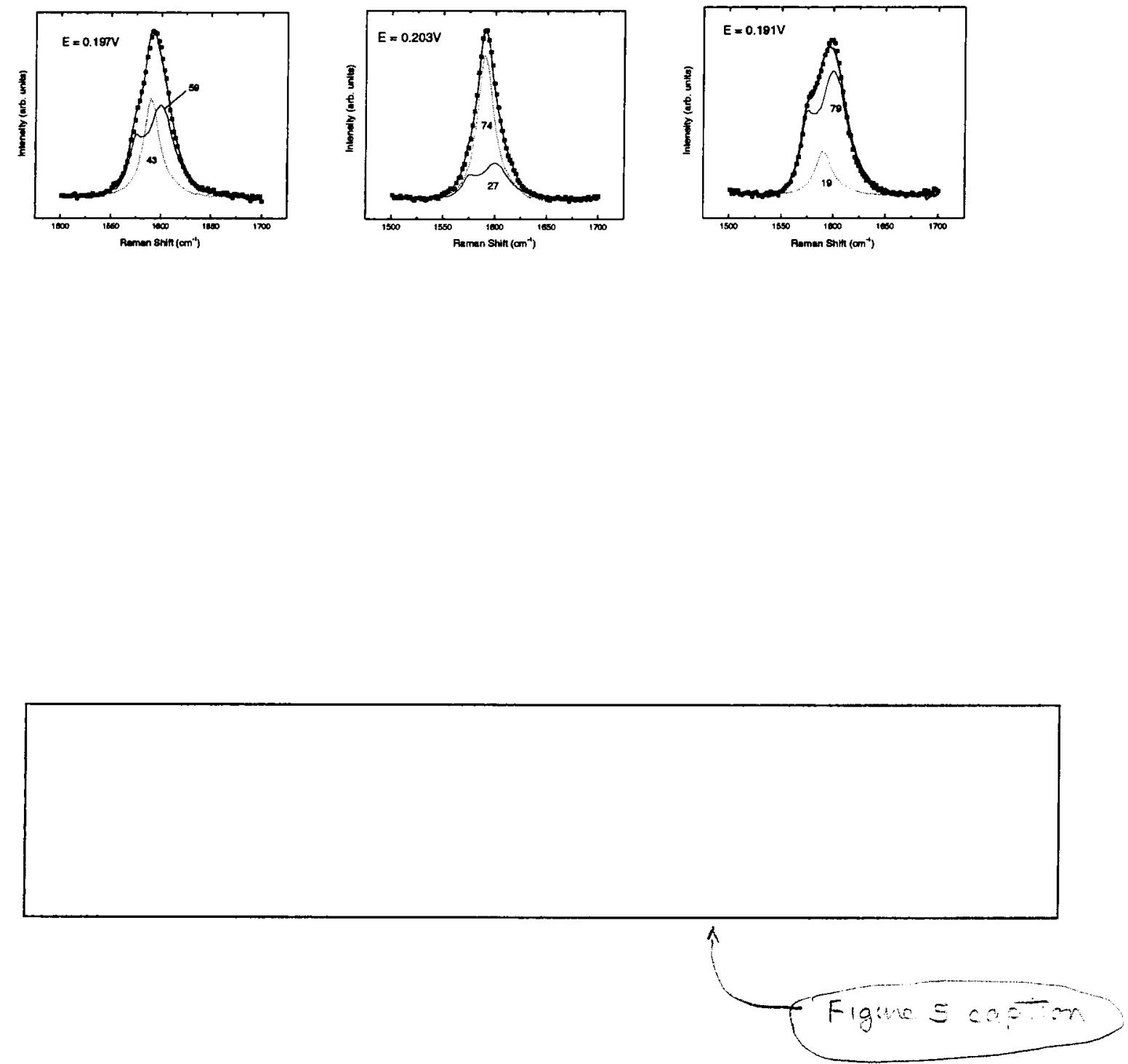


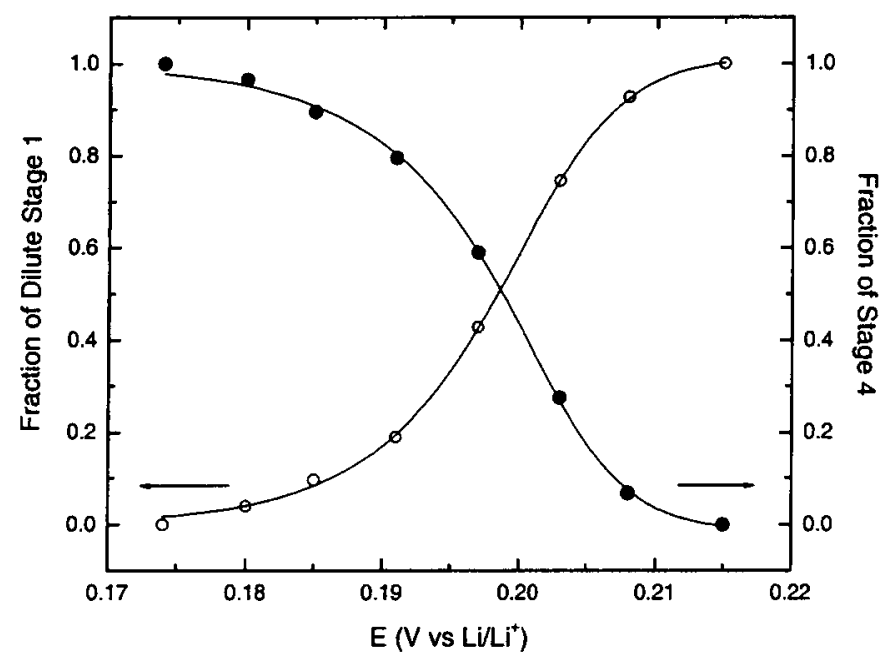

Fig. 6. Plots of amount of the fraction of dilute stage 1 (left ordinate) and stage 4 (right ordinate) determined independently based on the statistical analysis of spectral data as shown in Fig. 4. Stage 1 and stage 4 phases are given by the spectra recorded at $E=0.215$ and 0.157 , respectively. The solid lines are best fits the data using arbitrary non-linear functions. 


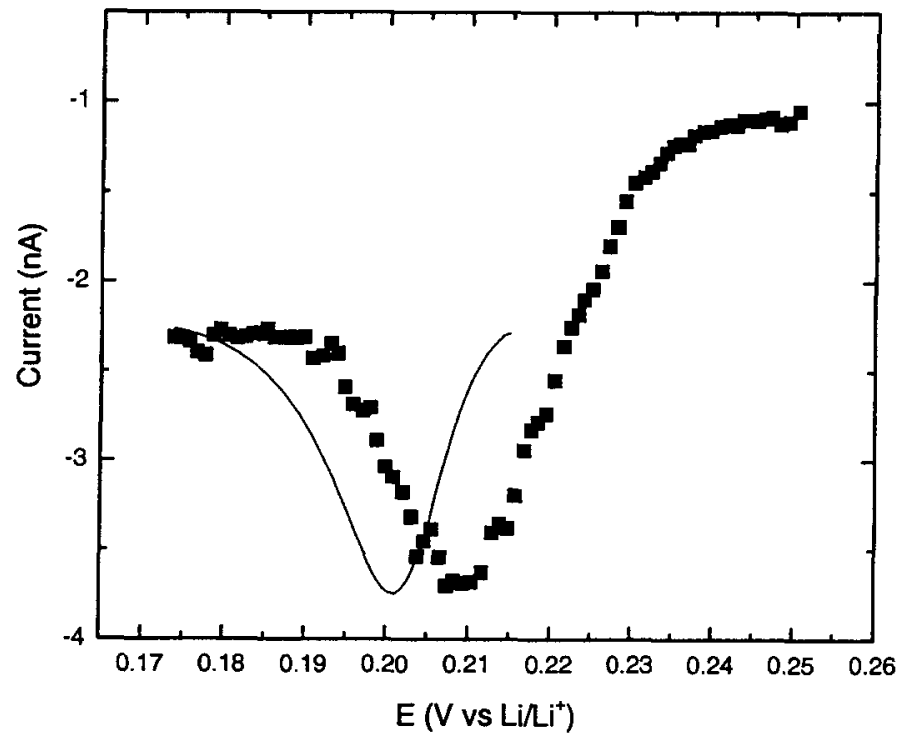

Fig. 7. Expanded plot of the voltammetric data in Fig. 2 in the range ca. $0.1725<E<$ $0.25 \mathrm{~V}$ (scattered points) and normalized voltammetric peak (solid line) as deduced from the statistical analyses of the spectroscopic data in Fig. 4 (see text for details). 

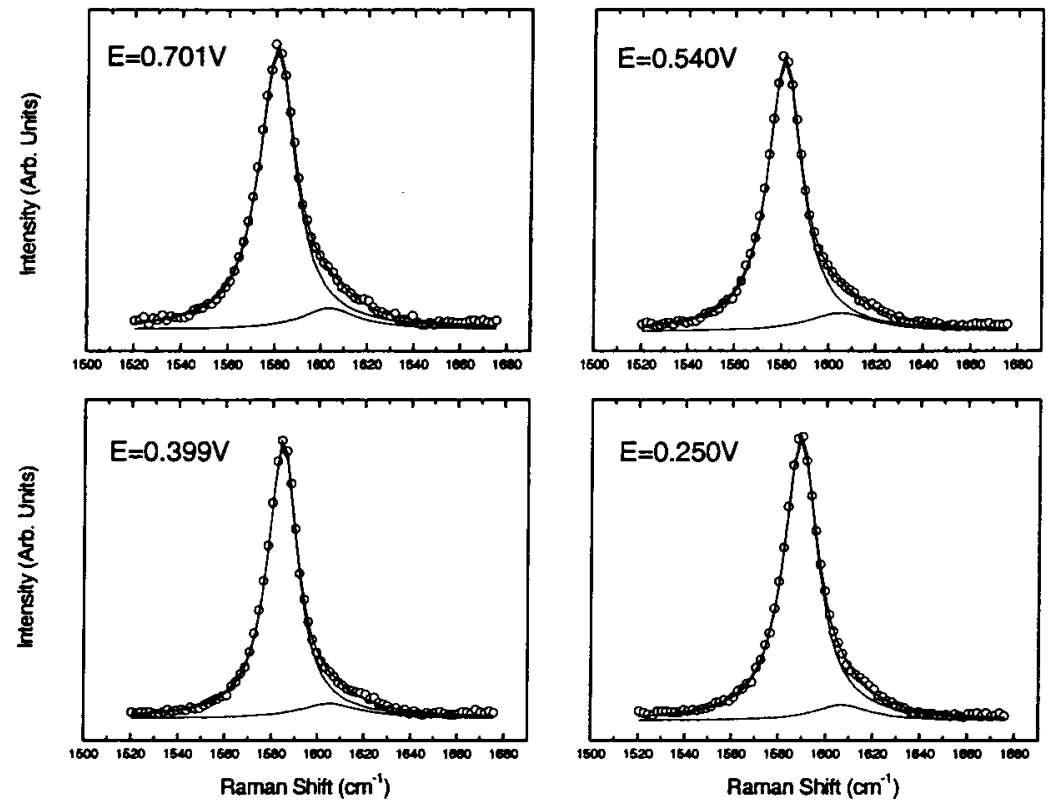

Fig. A. Deconvolution of four representative Raman spectra for the KS-44 microflake (see scattered points) in the potential region down to ca. $0.22 \mathrm{~V}$ in terms of the prominent $1580 \mathrm{~cm}^{-1}$ peak ascribed to the $E_{2 \mathrm{~g}^{2}}$ mode of graphite (dotted line) and an additional feature centered at about $1604 \mathrm{~cm}^{-1}(X)$ attributed to electrochemically induced irreversible changes in the graphite induced by $\mathrm{Li}^{+}-$ intercalation into the lattice during previous cycles (solid line) see text for additional details). The solid line through the scattered points represents the sum of the two best-fit components. 


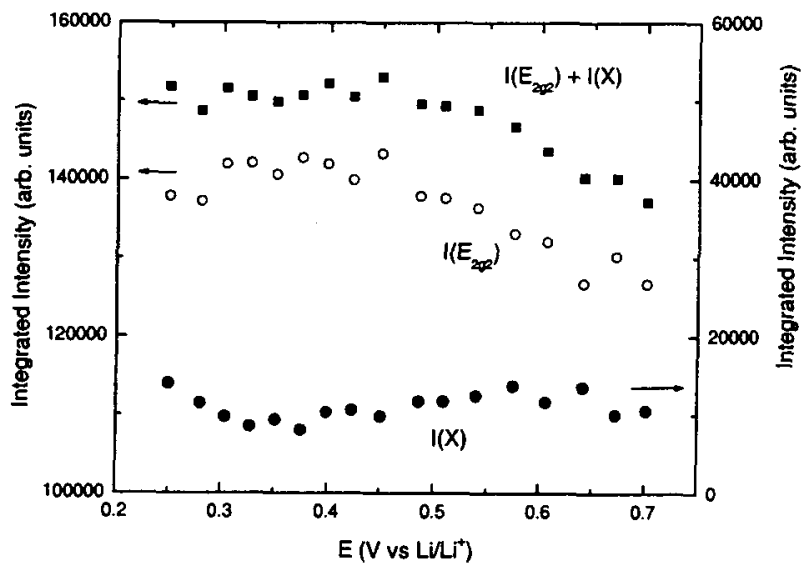

Fig. B. Plot of the integrated peak intensity (I) of the $\mathrm{E}_{2 \mathrm{~g} 2}$ (open circles, left ordinate) and $\mathrm{X}$ modes (solid circles, right ordinate) as a function of potential, extracted from a statistical analysis of spectra collected over the region $0.25-0.7 \mathrm{~V}$. Also shown in this figure is the total integrated intensity of the entire feature, i.e. $I\left(E_{2 g}\right)+I(X)$ (see solid squares, left ordinate). 